\title{
Relationship between SSRIs and Metabolic Syndrome Abnormalities in Patients with Generalized Anxiety Disorder: A Prospective Study
}

\author{
Murat Beyazyüz ${ }^{1}$, Yakup Albayrak ${ }^{2}{ }^{凶}$, Oğuzhan Bekir Eğilmez ${ }^{3}$, Neslihan Albayrak ${ }^{4}$ and Elmas Beyazyüz ${ }^{5}$ \\ ${ }^{1}$ Gölbaşı Hasvak State Hospital, Department of Psychiatry, Ankara, Turkey \\ ${ }^{2}$ Kırklareli State Hospital, Department of Psychiatry, Kırklareli, Turkey \\ ${ }^{3}$ Adıyaman State Hospital, Department of Psychiatry, Adıyaman, Turkey \\ ${ }^{4}$ Kırklareli State Hospital, Department of Cardiology, Kırklareli, Turkey \\ ${ }^{5}$ Ankara Numune Education and Research Hospital, Department of Psychiatry, Ankara, Turkey
}

Objective SSRIs are some of the most widely prescribed medications in the world. In addition to their effectiveness, SSRIs were reported to be associated with the side effects of weight gain, sexual dysfunction, drug interactions, extrapyramidal symptoms and discontinuation symptoms. However, the effects of SSRIs on metabolic parameters are poorly understood.

Methods This study aims to describe the effects of SSRIs on the metabolic parameters of drug-naive first episode patients with generalized anxiety disorder. Ninety-seven female patients aged 20-41 years without any metabolic or psychiatric comorbidity were included in the study. Fluoxetine, sertraline, paroxetine, citalopram and escitalopram were randomly given to the patients. Metabolic parameters, including BMI, waist circumference and the levels of fasting glucose, total cholesterol, triglyceride, HDL, LDL and blood pressure, were measured before and after 16 weeks of treatment.

Results In the paroxetine group, there was a significant increase in the parameters of weight, BMI, waist circumference, fasting glucose, total cholesterol, LDL and triglyceride after 16 weeks of treatment. There were significant increases in the levels of triglyceride in the citalopram and escitalopram groups. In the sertraline group, the total cholesterol level increased after treatment. In the fluoxetine group, there were significant reductions in the parameters of weight, total cholesterol and triglyceride.

Conclusion To our knowledge, this study is the first to prospectively describe metabolic syndrome abnormalities in patients with first episode generalized anxiety disorder. Although the effectiveness of the different SSRIs is similar, clinicians should be more careful when prescribing SSRIs to patients who have cardiac risk factors. Larger and lengthier controlled clinical trials are needed to explore the associations between SSRI use and metabolic syndrome.

Psychiatry Investig 2013;10:148-154

Key Words Metabolic syndrome, SSRI, Side effect, Prospective, Anxiety.

\section{INTRODUCTION}

Antidepressants are one of the most widely prescribed medications in the world. In 1998, the first SSRI, fluoxetine, was produced in the US. Fluoxetine was superior to tricyclic antidepressants (TCAs) in terms of reducing side effects and se-

Received: June 6, 2012 Revised: October 12, 2012

Accepted: December 20, 2012 Available online: May 30, 2013

$\square$ Correspondence: Yakup Albayrak, MD

Kurklareli State Hospital, Department of Psychiatry, Kırklareli Devlet Hastanesi, Psikiyatri Klinigi, 3901, Kırklareli, Turkey

Tel: +905056355434, Fax: +0312 2122243, E-mail: dr.fuge@hotmail.com

(a) This is an Open Access article distributed under the terms of the Creative Commons Attribution Non-Commercial License (http://creativecommons.org/licenses/by$\mathrm{nc} / 3.0$ ) which permits unrestricted non-commercial use, distribution, and reproduction in any medium, provided the original work is properly cited. lectivity for serotonin receptors, and it had a similar level of effectiveness as the TCAs. Other SSRIs were produced soon after the development of fluoxetine. ${ }^{1,2}$ Nevertheless, SSRIs were reported to be associated with many side effects, including weight gain, sexual dysfunction, drug interactions, extrapyramidal symptoms and discontinuation symptoms. ${ }^{3}$ As a decrease in appetite and weight loss are associated with depression, the side effects of increased appetite and weight gain were initially suggested to be due to recovery from depression. The SSRIs were initially associated with weight loss. However, the results of a randomized clinical study suggested that weight gain might be a side effect of long-term paroxetine use but not of the use of sertraline or fluoxetine., ${ }^{4,5} \mathrm{An}-$ other study reported that there was no difference between 
fluoxetine and placebo in terms of weight gain after one year of use. ${ }^{4}$ Currently, it is unclear whether all of the SSRIs induce weight gain.

Metabolic syndrome is described as a cluster of metabolic abnormalities that includes abdominal obesity, hypertriglyceridemia, low high-density lipoprotein (HDL), cholesterol, hypertension and hyperglycemia. Metabolic syndrome predisposes patients to cardiovascular disease (CVD) and diabetes mellitus. ${ }^{67}$ The prevalence of metabolic syndrome and individual cardiovascular risk factors, including obesity, dyslipidemia, diabetes mellitus, cigarette smoking, and hypercortisolemia, is greater in individuals with major mental illness compared to the general population. ${ }^{8-10}$ The relative likelihood of metabolic disturbances with atypical antipsychotics is well established; however, there is limited data available regarding the association between SSRI use and metabolic disturbances. Studies have investigated the association between SSRI use and weight gain, ${ }^{11-13}$ serum cholesterol level ${ }^{14,15}$ and body mass index. ${ }^{16,17}$ However, there is only one study that investigated the associations between SSRI use and all of the metabolic parameters according to the ATP-III criteria; in this study, Reader et al. ${ }^{18}$ reported an association between the use of SSRIs and abdominal obesity, hypercholesterolemia and a trend toward diabetes. In the subgroup analysis, paroxetine was found to be markedly associated with general and abdominal obesity but not with hypercholesterolemia. Only citalopram was suggested to have no association with metabolic abnormalities.

When researching the association between metabolic syndrome abnormalities and the agents used for treatment, it is very important to keep in mind the intrinsic effects of the disorders on metabolic parameters. In most studies that have investigated the link between depressive symptoms and metabolic syndrome, ${ }^{19-23}$ a positive association was reported, while some studies reported no association between the two factors. $^{24-26}$ There are only a few studies that focused on the association between anxiety and metabolic syndrome, ${ }^{27-30}$ of which only two confirmed a positive association. ${ }^{27,29}$ To our knowledge, there is only one study that specifically analyzed the association between metabolic syndrome and generalized anxiety disorder (GAD). In this study, Carroll et al..$^{29}$ reported that GAD was positively associated with metabolic syndrome. Thus, the evidence for an association between metabolic abnormalities and GAD might be weaker than for MDD. Therefore, in this study, we included only patients with GAD to minimize the confusing effects of the primary disorder on metabolic parameters.

In this study, we examined the association between metabolic syndrome parameters and the SSRIs paroxetine, escitalopram, fluoxetine, sertraline and citalopram in female pa- tients who were diagnosed with generalized anxiety disorder. The present study is the first to analyze the effects of SSRIs on metabolic parameters in drug-naive GAD patients during a 16-week follow-up period.

\section{METHODS}

\section{Subjects}

Two hundred and thirty-three drug-naive first admission patients who were between 20 and 41 years old were recruited from among the outpatients of Ankara Numune Education and Research Hospital. As there might be an independent effect of sex on metabolic parameters, eighty-one male patients were excluded from the study. Ten patients were excluded from study because they were taking another psychotropic medication and/or oral contraceptive treatment, had additional psychiatric diagnoses or abused alcohol. All subjects provided written informed consent for participation in the study after the procedure had been fully explained. The ethics committee of Ankara Numune Research and Education Hospital approved the present study. Diagnoses were made according to the DSM-IV criteria and were confirmed by two trained psychiatrists through the use of a Structured Clinical Interview (SCID-I and SCID-II) from the DSM-IV-TR. ${ }^{30,31}$ The interrater reliability of the diagnoses was confirmed statistically and was found to be insignificant $(\mathrm{p}=0.545)$. The SSRIs (paroxetine, fluoxetine, citalopram, sertraline and escitalopram) were randomly administered to the patients. Two patients from the citalopram group and one patient from the escitalopram group were excluded from the study due to discontinuation. Additionally, 41 patients who did not respond to SSRI treatment and switched to other psychotropic drugs, such as SNRIs, benzodiazepines, or TCAs, were excluded. In total, 97 patients were included in the present study. All of the patients who were included in the study were assessed biweekly. Patients were controlled for their food intake in terms of continuation of their usual eating habits during study. Blood samples were taken before and after sixteen weeks of treatment.

\section{Clinical assessments}

The presence of generalized anxiety disorder was diagnosed according to criteria set forth in the fourth edition of the Diagnostic and Statistical Manual for Mental Disorders (DSMIV). ${ }^{30,31}$ The severity of anxiety was assessed using the Hamilton Anxiety Scale (HAM-A). ${ }^{32}$ The HAM-A was one of the first rating scales developed to measure the severity of anxiety symptoms and is still widely used in both clinical and research settings. The scale consists of 14 items, each defined by a series of symptoms, and measures both psychic anxiety 
(mental agitation and psychological distress) and somatic anxiety (physical complaints related to anxiety). The validity and reliability of the HAM-A scale in Turkey was established by Yazic1 et al. ${ }^{33}$ The 17 -item version of the Hamilton Depression Rating Scale (HDRS) was used to assess severity of depression. ${ }^{34}$ The validity and reliability of the HDRS scale in Turkey was established by Akdemir et al. ${ }^{35}$

\section{Assessment of metabolic syndrome}

Metabolic syndrome was defined according to the updated definition of the American Heart Association and the National Heart, Lung and Blood Institutes National Cholesterol Education Program-Adult Treatment Panel III (NCEP-ATP III).$^{36}$ It requires the presence of three or more of the following criteria: i) abdominal obesity, i.e., waist circumference $\geq$ $102 \mathrm{~cm}$ in men and $\geq 88 \mathrm{~cm}$ in women; ii) hypertriglyceridemia, i.e., elevated triglyceride level ( $\geq 150 \mathrm{mg} / \mathrm{dL}$ ) or drug treatment for elevated triglycerides; iii) low high-density lipoprotein (HDL) cholesterol ( $\leq 40 \mathrm{mg} / \mathrm{dL}$ in $\mathrm{men}, \leq 50 \mathrm{mg} /$ $\mathrm{dL}$ in women) or drug treatment for reduced HDL cholesterol; iv) hypertension, i.e., elevated blood pressure ( $\geq 130 / 85$ $\mathrm{mm} \mathrm{Hg}$ ) or the use of antihypertensive medication; and v) hyperglycemia, i.e., elevated fasting glucose level $(\geq 110 \mathrm{mg} /$ $\mathrm{dL}$ ) or the use of anti-diabetic medication. Waist circumference was measured using a measuring tape at the central point between the lowest front rib and the highest front point of the pelvis while the patients were wearing light clothing. Triglycerides, HDL cholesterol, and glucose levels were determined using routine standardized laboratory methods after a mean overnight fast of 11:16 h (SD=1:50 h). Systolic and diastolic blood pressures were measured twice in the right arm during supine rest using the OMRON M4 IntelliSense (HEM752A; Omron Healthcare, Inc., Bannockburn, IL, USA) and were averaged.

\section{Statistical analyses}

Data were analyzed using the Statistical Package for the Social Sciences, PC version 16.0 (SPSS, Chicago, IL, USA). A confidence interval (CI) of $95 \%$ and a 2 -tailed $p$ value of less than 0.05 were considered to be statistically significant for all analyses. Variables were tested for homogeneity of variance using the Levene test and for normality of distribution by utilizing the Kolmogorov-Smirnov test. Differences between age groups were tested with a series of 1-way analyses of variance, whereas differences in marital status, employment status, family history of metabolic syndrome, and rate of smoking were assessed by a $\chi^{2}$ test. The Wilcoxon $\mathrm{T}$ test was used for assessing changes in the values of the metabolic parameters and the scores of the Hamilton Anxiety-Hamilton Depression Rating scale before and after treatment.

\section{RESULTS}

Table 1 shows the sociodemographic and clinical characteristics of the participants. The mean age of the participants was 30.6 years ( $\mathrm{SD}=6.4$ years), and all of the participants were female. Age, marital status, employment status, rate of smoking and family history of metabolic syndrome were similar

Table 1. Demographic and clinical characteristics of patients

\begin{tabular}{|c|c|c|c|c|c|c|c|}
\hline & & Sertraline & Fluoxetine & Paroxetine & Citalopram & Escitalopram & $\mathrm{p}$ \\
\hline Age (years) & & $26.2 \pm 4.7$ & $27.2 \pm 3.8$ & $27.5 \pm 3.1$ & $27.3 \pm 3.3$ & $28.3 \pm 4.3$ & 0.28 \\
\hline Family status & & & & & & & 0.84 \\
\hline Single & & $14(70 \%)$ & $9(45 \%)$ & $13(65 \%)$ & $10(55.6 \%)$ & $11(57.9 \%)$ & \\
\hline Married & & $6(30 \%)$ & $11(55 \%)$ & $7(35 \%)$ & $8(44.4 \%)$ & $8(42.1 \%)$ & \\
\hline Employment status & & & & & & & 0.55 \\
\hline Works regulary & & $14(70 \%)$ & $14(70 \%)$ & $13(65 \%)$ & $9(50 \%)$ & $9(47.4 \%)$ & \\
\hline Unemployed & & $6(30 \%)$ & $6(30 \%)$ & $7(35 \%)$ & $9(50 \%)$ & $10(52.6 \%)$ & \\
\hline \multirow[t]{2}{*}{ Family history of MS } & Yes & $7(35 \%)$ & $9(45 \%)$ & $8(40 \%)$ & $8(44.4 \%)$ & $8(42.1 \%)$ & 0.93 \\
\hline & No & $13(84.4 \%)$ & $11(55 \%)$ & $12(60 \%)$ & $10(55.6 \%)$ & $11(57.9 \%)$ & \\
\hline \multirow[t]{2}{*}{ Smoking } & Yes & $7(35 \%)$ & $6(30 \%)$ & $6(30 \%)$ & $5(27.8 \%)$ & $6(31.6 \%)$ & 0.62 \\
\hline & No & $13(65 \%)$ & $14(70 \%)$ & $14(70 \%)$ & $13(72.2 \%)$ & $13(68.4 \%)$ & \\
\hline \multirow[t]{2}{*}{ HAMA } & $\mathrm{BT}$ & $26.5 \pm 3.26$ & $25.8 \pm 3.21$ & $26.8 \pm 3.3$ & $26.1 \pm 3.4$ & $25.8 \pm 2.8$ & $<0.001$ \\
\hline & AT & $10.8 \pm 1.2$ & $11.4 \pm 1.6$ & $10.2 \pm 1.3$ & $11.7 \pm 1.4$ & $11.1 \pm 1.5$ & \\
\hline \multirow[t]{2}{*}{ HDRS } & $\mathrm{BT}$ & $3.3 \pm 0.85$ & $2.65 \pm 0.74$ & $2.45 \pm 0.32$ & $3.05 \pm 0.72$ & $2.75 \pm 0.81$ & NS \\
\hline & $\mathrm{AT}$ & $3.3 \pm 0.92$ & $2.55 \pm 0.87$ & $2.65 \pm 0.71$ & $2.95 \pm 0.71$ & $2.67 \pm 0.64$ & \\
\hline
\end{tabular}

MS: metabolic syndrome, BT: before treatment, AT: after treatment, HAMA: Hamilton Anxiety Rating Scale, HDRS: Hamilton Depression, Rating scale, NS: not significant 
Table 2. The effects of SSRIs on metabolic parameters after 16 weeks

\begin{tabular}{|c|c|c|c|c|c|c|}
\hline & Time & Fluoxetine & Sertraline & Paroxetine & Escitalopram & Citalopram \\
\hline \multirow[t]{3}{*}{ Weight (kg) } & 0 & $61.75 \pm 7.71$ & $58.45 \pm 6.83$ & $59.7 \pm 3.46$ & $59.47 \pm 5.05$ & $58.33 \pm 7.44$ \\
\hline & 16 weeks & $58.50 \pm 6.90$ & $58.40 \pm 6.96$ & $62.31 \pm 3.86$ & $58.73 \pm 5.69$ & $58.72 \pm 7.06$ \\
\hline & & $\mathrm{p}<0.001$ & $\mathrm{p}=0.180$ & $\mathrm{p}<0.001$ & $\mathrm{p}=0.180$ & $\mathrm{p}=0.336$ \\
\hline \multirow[t]{3}{*}{ BMI $\left(\mathrm{kg} / \mathrm{m}^{2}\right)$} & 0 & $22.77 \pm 3.37$ & $21.20 \pm 2.13$ & $21.65 \pm 1.72$ & $21.52 \pm 2.22$ & $21.56 \pm 2.84$ \\
\hline & 16 weeks & $21.59 \pm 3.14$ & $21.17 \pm 2.05$ & $22.61 \pm 2.09$ & $21.26 \pm 2.51$ & $21.71 \pm 2.79$ \\
\hline & & $\mathrm{p}<0.001$ & $\mathrm{p}=0.778$ & $\mathrm{p}<0.001$ & $\mathrm{p}=0.276$ & $\mathrm{p}=0.345$ \\
\hline \multirow[t]{3}{*}{ Waist C. (cm) } & 0 & $78.01 \pm 6.94$ & $73.82 \pm 6.19$ & $77.32 \pm 6.11$ & $77.42 \pm 5.91$ & $75.33 \pm 7.12$ \\
\hline & 16 weeks & $75.70 \pm 6.72$ & $73.71 \pm 6.09$ & $78.71 \pm 6.25$ & $76.36 \pm 6.71$ & $75.52 \pm 7.15$ \\
\hline & & $\mathrm{p}<0.001$ & $\mathrm{p}=0.625$ & $\mathrm{p}=0.002$ & $\mathrm{p}=0.052$ & $\mathrm{p}=0.512$ \\
\hline \multirow{3}{*}{$\begin{array}{l}\text { Fasting glucose } \\
(\mathrm{mg} / \mathrm{dL})\end{array}$} & 0 & $90.15 \pm 10.51$ & $94.80 \pm 13.46$ & $92.35 \pm 11.07$ & $94.26 \pm 12.69$ & $92.33 \pm 12.79$ \\
\hline & 16 weeks & $90.80 \pm 12.63$ & $98.15 \pm 16.63$ & $101.65 \pm 11.52$ & $98.26 \pm 13.28$ & $92.22 \pm 11.58$ \\
\hline & & $\mathrm{p}=0.925$ & $\mathrm{p}=0.422$ & $\mathrm{p}<0.001$ & $\mathrm{p}=0.432$ & $\mathrm{p}=0.828$ \\
\hline \multirow[t]{3}{*}{$\mathrm{TC}(\mathrm{mg} / \mathrm{dL})$} & 0 & $172.60 \pm 18.63$ & $160.90 \pm 21.39$ & $168.85 \pm 16.97$ & $167.21 \pm 19.01$ & $167.44 \pm 21.06$ \\
\hline & 16 weeks & $163.70 \pm 19.3$ & $164.75 \pm 23.19$ & $186.05 \pm 15.82$ & $166.31 \pm 20.14$ & $168.83 \pm 21.72$ \\
\hline & & $\mathrm{p}=0.001$ & $\mathrm{p}=0.027$ & $\mathrm{p}<0.001$ & $\mathrm{p}=0.354$ & $\mathrm{p}=0.710$ \\
\hline \multirow[t]{3}{*}{ LDL (mg/dL) } & 0 & $99.30 \pm 20.12$ & $93.65 \pm 22.12$ & $90.45 \pm 22.88$ & $97.10 \pm 22.15$ & $85.11 \pm 23.08$ \\
\hline & 16 weeks & $89.80 \pm 19.00$ & $92.40 \pm 23.52$ & $103.60 \pm 22.6$ & $96.21 \pm 21.48$ & $85.77 \pm 22.21$ \\
\hline & & $\mathrm{p}<0.001$ & $\mathrm{p}=0.821$ & $\mathrm{p}<0.001$ & $\mathrm{p}=0.408$ & $\mathrm{p}=0.565$ \\
\hline \multirow[t]{3}{*}{ HDL (mg/dL) } & 0 & $55.65 \pm 5.52$ & $54.80 \pm 4.39$ & $54.01 \pm 4.85$ & $53.63 \pm 4.48$ & $55.83 \pm 6.55$ \\
\hline & 16 weeks & $55.35 \pm 4.69$ & $55.31 \pm 4.37$ & $53.71 \pm 6.46$ & $53.73 \pm 4.65$ & $53.83 \pm 6.68$ \\
\hline & & $\mathrm{p}=0.746$ & $\mathrm{p}=0.684$ & $\mathrm{p}=0.322$ & $\mathrm{p}=0.775$ & $\mathrm{p}=0.160$ \\
\hline \multirow[t]{3}{*}{ TG (mg/dL) } & 0 & $110.90 \pm 21.19$ & $103.40 \pm 25.09$ & $92.25 \pm 19.41$ & $105.52 \pm 25.02$ & $90.55 \pm 21.34$ \\
\hline & 16 weeks & $104.00 \pm 20.92$ & $101.35 \pm 21.66$ & $129.95 \pm 40.61$ & $172.57 \pm 53.08$ & $109.44 \pm 28.46$ \\
\hline & & $\mathrm{p}=0.016$ & $\mathrm{p}=0.643$ & $\mathrm{p}<0.001$ & $\mathrm{p}<0.001$ & $\mathrm{p}=0.001$ \\
\hline \multirow{3}{*}{$\begin{array}{l}\text { Blood pressure } \\
(\mathrm{mm} \mathrm{Hg})(\mathrm{S})\end{array}$} & 0 & $122.31 \pm 16.11$ & $110.92 \pm 15.01$ & $121.80 \pm 10.91$ & $125.43 \pm 12.81$ & $115.80 \pm 14.01$ \\
\hline & 16 weeks & $119.43 \pm 17.30$ & $116.13 \pm 12.20$ & $110.93 \pm 17.10$ & $122.40 \pm 17.62$ & $119.00 \pm 15.00$ \\
\hline & & $\mathrm{p}=0.54$ & $\mathrm{p}=0.24$ & $\mathrm{p}=0.143$ & $\mathrm{p}=0.56$ & $\mathrm{p}=0.34$ \\
\hline \multirow{3}{*}{$\begin{array}{l}\text { Blood pressure } \\
(\mathrm{mm} \mathrm{Hg})(\mathrm{D})\end{array}$} & 0 & $80.80 \pm 8.31$ & $82.81 \pm 8.40$ & $80.81 \pm 8.30$ & $80.60 \pm 8.09$ & $80.71 \pm 8.21$ \\
\hline & 16 weeks & $81.30 \pm 7.92$ & $81.01 \pm 7.63$ & $80.33 \pm 8.92$ & $79.31 \pm 8.93$ & $81.22 \pm 7.93$ \\
\hline & & $\mathrm{p}=0.64$ & $\mathrm{p}=0.44$ & $\mathrm{p}=0.74$ & $\mathrm{p}=0.34$ & $\mathrm{p}=0.52$ \\
\hline
\end{tabular}

BMI: body mass index, Waist C: waist circumference, TC: total cholesterol, LDL: low-density lipoprotein, HDL: high-density lipoprotein, TG: triglyceride, S: systolic, D: diastolic

between the groups ( $p>0.05)$. The mean dosages of sertraline, fluoxetine, paroxetine, citalopram, and escitalopram were $77.5 \pm 19.7 \mathrm{mg}, 28.5 \pm 9.3 \mathrm{mg}, 28.8 \pm 8.8 \mathrm{mg}, 31.1 \pm 8.2 \mathrm{mg}$ and $15.5 \pm 7.3 \mathrm{mg}$, respectively. The scores of the Hamilton Anxiety Rating Scale were reduced significantly in each treatment group $(\mathrm{p}<0.001)$. The scores of the Hamilton Depression Rating Scale were similar before and after treatment in all groups $(\mathrm{p}>0.05)$.

Table 2 shows the effects of each SSRI on metabolic parameters. In the fluoxetine group, there was a significant reduction in the parameters of weight $(p<0.001)$, BMI $(p<0.001)$, waist circumference $(\mathrm{p}<0.001)$, total cholesterol $(\mathrm{p}=0.001)$, LDL $(p<0.001)$ and TG $(p=0.016)$ after sixteen weeks of treatment. The parameters of blood pressure, levels of fasting glu- cose and HDL were similar before and after treatment (respectively, $\mathrm{p}=0.64 ; \mathrm{p}=0.925 ; \mathrm{p}=0.74$ ). In the sertraline group, only the level of total cholesterol was significantly increased after treatment $(\mathrm{p}=0.64)$. The other parameters of metabolic syndrome, including weight, BMI, waist circumference, LDL, TG, blood pressure, fasting glucose, and HDL, were similar before and after treatment in the sertraline group ( $p>0.05)$. In the paroxetine group, there was a significant increase in the parameters of weight $(\mathrm{p}<0.001)$, BMI $(\mathrm{p}<0.001)$, waist circumference ( $\mathrm{p}=0.002)$, fasting glucose $(\mathrm{p}<0.001)$, total cholesterol $(\mathrm{p}<0.001)$, LDL $(\mathrm{p}<0.001)$ and TG $(\mathrm{p}<0.001)$ after treatment. The parameters of blood pressure and level of HDL were found to be similar before and after treatment $(p>0.05)$. The level of TG increased significantly in patients who recei- 
ved escitalopram for sixteen weeks $(\mathrm{p}<0.001)$. In the citalopram group, only the level of TG increased significantly after treatment $(\mathrm{p}=0.001)$, and the other parameters of metabolic syndrome were similar before and after treatment $(p>0.05)$. At the end of the follow-up period, the Hamilton anxiety scale scores were significantly decreased in all groups $(\mathrm{p}<0.001)$.

\section{DISCUSSION}

Metabolic syndrome refers to the clustering of cardiovascular risk factors, such as diabetes, obesity, dyslipidemia and hypertension. ${ }^{6,37}$ This clustering of risk factors, which are not thought to be grouped by chance alone, are frequently seen in everyday clinical practice. Approximately 1 out of every 4 or 5 adults, depending on country, has metabolic syndrome. The incidence of metabolic syndrome increases with age; it has been estimated that metabolic syndrome affects more than $40 \%$ of the population over age 50 in the United States and nearly $30 \%$ of the population over age 50 in Europe. Metabolic syndrome has been commonly accepted as a simple clinical tool for the early detection of type 2 diabetes and cardiovascular disease. It has been estimated that people with metabolic syndrome are at twice the risk of developing cardiovascular disease compared to those without the syndrome and experience a five-fold increased risk for developing type 2 diabetes. ${ }^{38,39}$

Risk factors for cardiovascular disorders and the rates of physical disorders are increased in the psychiatric population, partly due to low levels of help-seeking ${ }^{40}$ and lifestyle factors, such poor diet, reduced physical activity and smoking. ${ }^{41,42}$ Therefore, treatment strategies for patients who suffer from mental illness should not put them at risk for metabolic syndrome. Thus, more research regarding the metabolic side effects of psychotropic drugs is needed. Attention to the metabolic side effects of antipsychotics has become more established; however, consideration of the metabolic side effects associated with antidepressants is poorer compared to antipsychotics, even though antidepressants are more commonly used than antipsychotics. This attitude might be associated with the longer treatment duration of antipsychotics compared to antidepressants.

Clinical presentation of depression vary from one person to another and may change over time. Significant weight loss or weight gain and decreased or incresed appetite are common symptoms for the depressed subjects. It can be asserted that the most reliable somatic indicators of depressive disorder include anorexia and weight loss. Besides a hypothalamic-based disturbance in depression, anorexia might be a secondary result of blunted olfactory and taste sensations. In the wide context of anhedonia, eating might also became less pleasing ac- tivity. Weight gain, a sypmtom which is especially seen in atypical depression, might be the result of decreased activity as well as overeating habits. This might cause aggrevation of preexisting diabetes, hypertension or coronary heart disease, especially in patients who have disposition. ${ }^{43,44}$ It is important to recognize that it is also an established risk factor for cardiovascular disease and several features of the metabolic syndrome, particularly hypertension, abdominal obesity and low HDL cholesterol. ${ }^{45}$ Furthermore, it is an evidence based fact that depression is associated with an increased risk for the development of type 2 diabetes. ${ }^{45,46}$ Thus, we had to exclude patients who suffered from major depresive disorder in order to eliminate the confounding effects of depression on our results.

In the literature, there is only one study that investigated whether subjects taking antidepressants were more likely to have elements of metabolic syndrome compared to subjects who were not taking psychotropic agents. In this cross sectional study, an association was reported between SSRI use and diabetes. In the subgroup analyses, paroxetine use was found to be markedly associated with both abdominal and general obesity. Citalopram was reported to be safe in terms of metabolic syndrome. However, fluoxetine, fluvoxamine and sertraline were assessed as a mixed group and have been reported to be associated with abdominal obesity and hypercholesterolemia. $^{18}$

In our study, fluoxetine was found to be the safest SSRI in terms of metabolic syndrome. Furthermore, at the end of the follow-up period, there were significant reductions in the parameters of weight, BMI, waist circumference, total cholester$\mathrm{ol}, \mathrm{LDL}$ and TG. Our finding is partially in contrast to that of Reader and et al., who found that fluoxetine was associated with abdominal obesity and hypercholesterolemia. ${ }^{18}$ These contrasting findings are most likely due to differences in the methodologies of the studies. However, a recent meta-analysis that investigated the metabolic effects of fluoxetine in patients with type-2 DM suggested that fluoxetine was associated with weight loss and reductions in the fasting glucose level, $\mathrm{HbAlc}$ and $\mathrm{TG}^{47}$ Our findings are in line with the results of this recent meta-analysis.

Our results showed that only the lipid profile of the patients was changed after treatment with citalopram and sertraline. While the total cholesterol level increased in the sertraline group, the level of TG was significantly elevated in the citalopram group. These findings partially replicated the findings of Reader et al.; however, citalopram cannot be described as purely safe in terms of its effects on lipid profile. ${ }^{18}$ To our knowledge, our finding is the first to describe an association between citalopram use and increased serum TG. Escitalopram, which has a similar molecular structure to that of citalopram, was found to significantly increase serum TG levels 
after sixteen weeks of use. However, the waist circumference of these patients was reduced after treatment. Thus, the metabolic effects of citalopram and escitalopram should be considered to be independent from weight gain.

At the end of the follow-up period, paroxetine affected all the parameters of metabolic syndrome except serum HDL level and blood pressure. Our findings replicated the findings of Reader et al. ${ }^{18}$ and Fava et al.. ${ }^{48}$ in which weight gain was reported 26 and 32 weeks after paroxetine treatment. Furthermore, in a recent meta-analysis by Serretti and Mandelli, ${ }^{49}$ it was reported that paroxetine use was associated with weight gain. Thus, our findings also supported the studies data in which paroxetine was reported to be associated with weight gain. However, the effects of paroxetine on metabolic parameters cannot be clearly explained.

Our study is the first to describe metabolic syndrome abnormalities in patients with first episode generalized anxiety disorder using a naturalistic follow-up treatment. Researching the effects of any drug on human metabolism is complicated due to a number of co-variants. Thus, in the present study, we attempted to exclude some co-variants, such as sex, advanced age, comorbid psychiatric or metabolic disorder, and exposure to other drugs, to demonstrate the most probable effects of SSRIs on metabolic syndrome parameters.

Our study has some limitations. First, the sample sizes for each group might be too small to make a general statement regarding the results. Smoking more than 20 cigarettes per day has been found to be associated with a higher risk of MS in European and Asian populations. Smoking increases the risk of MS via the development of abdominal obesity and insulin resistance. ${ }^{50}$ However, the association between smoking and MS is controversial. Two cross-sectional studies in Portugal and Japan found that there was no association between smoking and MS. ${ }^{51,52}$ In our study, $33 \%$ of the patients were smokers; however, all the groups were similar in terms of smoking habits. Thus, smoking may be considered a relative limitation. In a large, population-based study, parental histories of hypertension, diabetes and stroke were reported to be three independent predictors of MS. ${ }^{53}$ We could not exclude this confounding effect as a family history of MS was similar among the groups. As a result, a family history of MS could be accepted as a relative limitation. The duration of the followup period is another limitation. We can only make conclusions regarding the short-term effects of SSRIs on metabolic parameters. Another limitation was that fluvoxamine is not approved for generalized anxiety disorder in Turkey; therefore, we could not examine its effects on metabolic syndrome parameters.

SSRIs are used worldwide for the treatment of various psychiatric disorders. The association between metabolic syn- drome and the use of SSRIs is not well established. In this study, we showed the different metabolic effects of SSRIs on metabolic parameters during a short-term follow-up period, and we also attempted to draw attention to the metabolic effects of SSRIs. Larger controlled clinical trials of a longer duration are needed to explore the associations between SSRI use and metabolic syndrome. More attention should be given to patients receiving SSRIs who have cardiovascular risk factors, and the effects of SSRIs on the parameters of metabolic syndrome should be carefully monitored during treatment.

\section{REFERENCES}

1. Olfson M, Marcus SC, Pincus HA, Zito JM, Thompson JW, Zarin DA. Antidepressant prescribing practices of outpatient psychiatrists. Arch Gen Psychiatry 1998;55:310-316.

2. Sclar DA, Robison LM, Skaer TL, Dickson WM, Kozma CM, Reeder CE. Antidepressant prescribing patterns: a comparison of blacks and whites in a medicaid population. Clin Drug Investig 1998;16:135-140.

3. Masand PS, Gupta S. Long-term side effects of newer-generation antidepressants: SSRIS, venlafaxine, nefazodone, bupropion, and mirtazapine. Ann Clin Psychiatry 2002;14:175-182.

4. Michelson D, Amsterdam JD, Quitkin FM, Reimherr FW, Rosenbaum JF, Zajecka J, et al. Changes in weight during a 1-year trial of fluoxetine. Am J Psychiatry 1999;156:1170-1176.

5. de Jonghe F, Ravelli DP, Tuynman-Qua H. A randomized, double-blind study of fluoxetine and maprotiline in the treatment of major depression. Pharmacopsychiatry 1991;24:62-67.

6. Grundy SM. Metabolic syndrome pandemic. Arterioscler Thromb Vasc Biol 2008;28:629-636.

7. Cameron AJ, Shaw JE, Zimmet PZ. The metabolic syndrome: prevalence in worldwide populations. Endocrinol Metab Clin North Am 2004; 33:351-375.

8. Grant BF, Hasin DS, Chou SP, Stinson FS, Dawson DA. Nicotine dependence and psychiatric disorders in the United States: results from the national epidemiologic survey on alcohol and related conditions. Arch Gen Psychiatry 2004;61:1107-1115.

9. Hagg S, Lindblom Y, Mjorndal T, Adolfsson R. High prevalence of the metabolic syndrome among a Swedish cohort of patients with schizophrenia. Int Clin Psychopharmacol 2006;21:93-98.

10. McEvoy JP, Meyer JM, Goff DC, Nasrallah HA, Davis SM, Sullivan L, et al. Prevalence of the metabolic syndrome in patients with schizophrenia: baseline results from the Clinical Antipsychotic Trials of Intervention Effectiveness (CATIE) schizophrenia trial and comparison with national estimates from NHANES III. Schizophr Res 2005;80:19-32.

11. Sussman N, Ginsberg D. Rethinking side effects of the selective serotonin reuptake inhibitors: sexual dysfunction and weight gain. Psychiatr Ann 1998;28:89-97.

12. Mackle MKJ, Kocsis J. Effects on body weifght of the SSRI citalopram. Las Croabas, Puerto Rico: Scientific abstract of the 37th Annual Meeting of the American College of Neuropsychopharmacology, Dec 14-18, 1998.

13. Bouver CD, Harvey BH. Phasic craving for carbohydrate observed with citalopram. Int Clin Psychopharmacol 1996;11:273-278.

14. Bailey DL, Melledo JM. Effects of selective serotonin reuptake inhibitors on cholesterol levels in patients with panic disorder. J Clin Psychopharmacol 2003;23:317-319.

15. Kim EJ, Yu BH. Increased cholesterol levels after paroxetine treatment in patients with panic disorder. J Clin Psychopharmacol 2005;25:597599.

16. Pine DS, Goldstein RB, Wolk S, Weissman MM. The association between childhood depression and adulthood body mass index. Pediat- 
rics 2001;107:1049-1056.

17. Berlin I, Lavergne F. Relationship between body-mass index and depressive symptoms in patients with major depression. Eur Psychiatry 2003; 18:85-88.

18. Reader MB, Bjelland I, Emil Vollset S, Steen VM. Obesity, dyslipidemia and diabetes with selective serotonin reuptake inhibitors: the Hordaland health study. J Clin Psychiatry 2006;67:1974-1982.

19. Kinder LS, Carnethon MR, Palaniappan LP, King AC, Fortmann SP. Depression and the metabolic syndrome in young adults: findings from the Third National Health and Nutrition Examination Survey. Psychosom Med 2004;66:316-322.

20. Lehto SM, Heiskanen T, Hintikka J, Niskanen L, Koivumaa-Honkanen $\mathrm{H}$, Tolmunen $\mathrm{T}$, et al. Metabolic syndrome - the impact of depression. Ann Epidemiol 2008;18:871.

21. Koponen H, Jokelainen J, Keinanen-Kiukaanniemi S, Kumpusalo E, Vanhala M. Metabolic syndrome predisposes to depressive symptoms: a population-based 7-year follow-up study. J Clin Psychiatry 2008;69: 178-182.

22. Vanhala M, Jokelainen J, Keinanen-Kiukaanniemi S, Kumpusalo E, Koponen $\mathrm{H}$. Depressive symptoms predispose females to metabolic syndrome: a 7-year follow-up study. Acta Psychiatr Scand 2008;119:137142 .

23. Dunbar JA, Reddy P, Davis-Lameloise N, Philpot B, Laatikainen T, Kilkkinen A, et al. Depression: an important comorbidity with metabolic syndrome in a general population. Diabetes Care 2008;31:23682373.

24. Miettola J, Niskanen LK, Viinamaki H, Kumpusalo E. Metabolic syndrome is associated with self-perceived depression. Scand J Prim Health Care 2008;26:203-210.

25. Muhtz C, Zyriax BC, Klahn T, Windler E, Otte C. Depressive symptoms and metabolic risk: effects of cortisol and gender. Psychoneuroendocrinology 2009;34:1004-1011.

26. Hildrum B, Mykletun A, Midthjell K, Ismail K, Dahl AA. No association of depression and anxiety with the metabolic syndrome: the Norwegian HUNT study. Acta Psychiatr Scand 2009;120:14-22.

27. Skilton MR, Moulin P, Terra JL, Bonnet F. Associations between anxiety, depression, and the metabolic syndrome. Biol Psychiatry 2007;62: 1251-1257.

28. Raikkonen K, Matthews KA, Kuller LH. The relationship between psychological risk attributes and the metabolic syndrome in healthy women: antecedent or consequence? Metabolism 2002;51:1573-1577.

29. Carroll D, Phillips AC, Thomas GN, Gale CR, Deary I, Batty GD. Generalized anxiety disorder is associated with metabolic syndrome in the Vietnam experience study. Biol Psychiatry 2009;66:91-93.

30. American Psychiatric Assosiation. Diagnostic and Statistical Manual of Mental Disorders, 4 th Edition, Text Revsion. Washington DC: American Psychiatric Assosiation; 2000.

31. World Health Organization (WHO). The Composite International Diagnostic Interview (CIDI). Geneva: WHO; 1997.

32. Hamilton M. Development of a rating scale for primary depressive illness. Br J Soc Clin Psychol 1967;6:278-296.

33. Yazıcı MK, Başaran D, Tanrıverdi N ve ark. Hamilton Anksiyete Değerlendirme Ölçeği, değerlendiriciler arası güvenilirlik ve geçerlik çalışması. Türk Psikiyatri Dergisi 1998;9:114-117.

34. Hamilton M. A rating scale for depression. J Neurol Neurosurg Psychiatry 1960;23:56-62.

35. Akdemir A, Orsel SD, Dag I, Turkcapar MH, Iscan N, Ozbay H. The validity and reliability of the Hamilton Depression Rating Scale and its clinical use. Psikiyatri Psikol Psikofarmakol Derg 1996;4:251-259.

36. Grundy SM, Cleeman JI, Daniels SR, Donato KA, Eckel RH, Franklin BA, et al. Diagnosis and management of the metabolic syndrome: an American Heart Association/National Heart, Lung, and Blood Institute Scientific Statement. Circulation 2005;112:2735-2752.

37. National Cholesterol Education Program (NCEP) Expert Panel on Detection, Evaluation, and Treatment of High Blood Cholesterol in Adults (Adult Treatment Panel III). Third Report of the National Cholesterol Education Program (NCEP) Expert Panel on Detection, Evaluation, and Treatment of High Blood Cholesterol in Adults (Adult Treatment Panel III) final report. Circulation 2002;106:3143-3421.

38. Ford ES, Giles WH, Mokdad AH. Increasing prevalence of the metabolic syndrome among U.S. adults. Diabetes Care 2004;27:2444-2449.

39. Whooley MA, de Jonge P, Vittinghoff E, Otte C, Moos R, Carney RM, et al. Depressive symptoms, health behaviors, and risk of cardiovascular events in patients with coronary heart disease. JAMA 2008;300:23792388.

40. Phelan M, Seller J, Leese M. The routine assessment of severity amongst people with mental illness. Soc Psychiatry Psychiatr Epidemiol 2001;36: 200-206.

41. Lesage AD, Goering P, Lin E. Family physicians and the mental health system. Report from the Mental Health Supplement to the Ontario Health Survey. Can Fam Physician 1997;43:251-256.

42. Brown S, Inskip H, Barraclough B. Causes of the excess mortality of schizophrenia. Br J Psychiatry 2000;177:212-217.

43. Mast BT, Neufeld S, MacNeill SE, Lichtenberg PA. Longitudinal support for the relationship between vascular risk factors and late-life depressive symptoms. Am J Geriatr Psychiatry 2004;12:93-101.

44. Davidson JR, Miller RD, Turnbull CD, Sullivan JL. Atypical depression. Arch Gen Psychiatry 1982;39:527-534.

45. Ciechanowski PS, Katon WJ, Russo JE. Depression and diabetes: impact of depressive symptoms on adherence, function, and costs. Arch Intern Med 2000;160:3278-3285.

46. Katon WJ, Russo JE, Von Korff M, Lin EH, Ludman E, Ciechanowski PS. Long-term effects on medical costs of improving depression outcomes in patients with depression and diabetes. Diabetes Care 2008; 31:1155-1159.

47. Ye Z, Chen L, Yang Z, Li Q, Huang Y, He M, et al. Metabolic effects of fluoxetine in adults with type 2 diabetes mellitus: a meta-analysis of randomized placebo-controlled trials. PLoS One 2011;6:e21551.

48. Fava M, Judge R, Hoog SL, Nilsson ME, Koke SC. Fluoxetine versus sertraline and paroxetine in major depressive disorder: changes in weight with long-term treatment. J Clin Psychiatry 2000;61:863-867.

49. Serretti A, Mandelli L. Antidepressants and body weight: a comprehensive review and meta-analysis. J Clin Psychiatry 2010;71:1259-1272.

50. Wilsgaard T, Jacobsen BK. Lifestyle factors and incident metabolic syndrome The Tromso Study 1979-2001. Diabetes Res Clin Pract 2007;78: 217-224.

51. Santos AC, Ebrahim S, Barros H. Alcohol intake, smoking, sleeping hours, physical activity and the metabolic syndrome. Prev Med 2007; 44:328-334.

52. Katano S, Nakamura Y, Nakamura A, Murakami Y, Tanaka T, Nakagawa $\mathrm{H}$, et al. Relationship among physical activity, smoking, drinking and clustering of the metabolic syndrome diagnostic components. J Atheroscler Thromb 2010;17:644-650.

53. Cai H, Huang J, Xu G, Yang Z, Liu M, Mi Y, et al. Prevalence and determinants of metabolic syndrome among women in Chinese rural areas. PLoS One 2012;7:e36936. 